\title{
Correction to: Bank-insurer-firm tripartite interconnectedness of credit risk exposures in a cross-shareholding network
}

\section{Masayasu Kanno ${ }^{1}$}

Published online: 17 July 2018

(C) Springer Nature Limited 2018

\section{Correction to: Risk Manag https://doi.org/10.1057/s41283-018-0033-4}

In the 'Introduction' section a part of a sentence was omitted. The paragraph should be read:

Section 2 reviews prior literature on cross-shareholding and interconnectedness in various financial networks. Section 3 contains the credit risk analysis using some measures. Section 4 presents the network structure analysis of cross-shareholding. Section 5 conducts stress test and Sect. 6 concludes the study.

The authors apologise for their error.

The original article can be found online at https://doi.org/10.1057/s41283-018-0033-4.

Masayasu Kanno

kanno.masayasu@nihon-u.ac.jp

1 College of Commerce, Nihon University, Tokyo 157-8570, Japan 